\title{
Local growth charts for an Iranian child population aged 2-5 years in comparison with the World Health Organization Child Growth Standards
}

\author{
Zahra Heidari ${ }^{1,2}$, Awat Feizi $i^{1,2,3^{*}}$ (D) Sara Rezaei ${ }^{1}$ (1) and Roya Kelishadi ${ }^{4^{*}}$ (D)
}

\begin{abstract}
Background: There are no national reference charts in Iran for children aged under five. This study aimed to develop representative growth reference charts of height, weight, and BMI for children aged 2-5 years in Isfahan, Iran, and to compare them with the WHO reference curves.

Results: This population-based study has a combination of longitudinal and cross-sectional design. It included 1325 and 761 healthy children, who were born between 2002 and 2015 in Isfahan, central Iran, in longitudinal and crosssectional phases. Expert health care providers measured the height and weight of children in health centers. The lambda-mu-sigma method was used to construct the age- and sex-specific growth charts of anthropometric measures. The study sample comprised 1029 boys and 1057 girls. The centiles of height, weight, and BMl of boys were higher than that of girls in all age groups. The weight patterns of studied children were close to those of the WHO references in the lower percentiles. However, our study children, especially girls, were lighter compared with WHO standards based on the middle and upper percentiles of the weight distribution. Compared with WHO standards, boys of our study were taller especially at older ages. The percentiles of the BMl for our study samples were considerably lower than WHO standards.

Conclusion: There are differences between our local growth charts for weight, height, and BMI with WHO standards. The local growth standards could be more precise for assessing growth problems in local and national settings. Due to notable differences between our results with WHO standards, future studies are warranted for constructing nationwide growth charts.
\end{abstract}

Keywords: Growth reference charts, WHO standards, Anthropometric measures, LMS method, Isfahan

\section{Background}

Growth is a sensitive indicator of the health of infants and children. Growth assessment plays a pivotal role in child health monitoring. Growth failure, nutritional disorders, chronic illness, and social deprivation can be

\footnotetext{
* Correspondence: awat feiz@hlth.mui.ac.ir; roya.kelishadi@gmail.com Awat Feizi and Roya Kelishadi contributed equally to this work and share cocorresponding authorship on this study.

'Department of Biostatistics and Epidemiology, School of Health, Isfahan University of Medical Sciences, Isfahan, Iran

${ }^{4}$ Department of Pediatrics, Child Growth and Development Research Center, Research Institute for Primordial Prevention of Non-communicable Diseases, Isfahan University of Medical Sciences, Hezar-Jerib Ave., Isfahan 81746-73461, Iran

Full list of author information is available at the end of the article
}

detected early through growth monitoring $[1,2]$. Growth charts in the form of curves or tables allow the visual inspection of anthropometric parameters and are widely used to evaluate the growth and health status of children and adolescents. They play an essential role in the detection and assessment of abnormalities in growth and development $[1,3,4]$.

Although international growth charts for anthropometric indices exist such as Centers for Disease Control and Prevention (CDC) Growth Charts and the World Health Organization (WHO) Child Growth Standards (WHO-CGS), national and local continent growth charts are unavailable in many countries. Although some 
countries had their own growth curves or have adopted the WHO growth charts, few countries did not adopt them, and some countries such as the USA partially adopted the new growth standards for age under 2 years; in some instance, the European Society for Pediatric Gastroenterology, Hepatology and Nutrition Committee on Nutrition directly recommends that the WHO reference charts should be adopted for 0-5-year-old children in Europe [5-7]. However, it should be noted that the World Health Organization (WHO) growth standards for children aged $0-5$ years were established by data from six countries (USA, Norway, Brazil, Ghana, India, and Oman) with sampling from children living under the optimal environment for growth such as breastfed, nonsmoking mother, and adequate access to healthcare [8-11]. Despite of the CDC and WHO growth reference charts are commonly used in some countries, their applicability is challenging due to the diversity in cultural, economic, social, and environmental factors such as diet and health care services and genetic background, all influence the growth of people. Accordingly, growth assessment in children can be improved by considering all the abovementioned influential factors through establishing the local and national growth references [9-11]. Therefore, many countries, such as Norway, the UK, China, Taiwan, Saudi Arabia, and Japan, had established their own growth references [3].

There are no national reference charts in Iran for children aged under five; although, in recent years some local growth charts have been developed in Iran [1217], they did not evaluate and construct the reference charts for all common anthropometric indices and majority of them focused only on one measure or specific age group such as newborns and, more importantly, lack on considering the reliable protocol for evaluating the reference chart for children under 5 years particularly tracking the growth from 24 to 60 months. Here, we developed growth references charts for all three anthropometric measures, i.e., height-for-age, weight-for-age, and BMI-for-age based on a large sample representative local data for children living in Isfahan, the biggest city located in the center and the third biggest city of Iran, aged 2-5years and compared these references with those reported by WHO.

\section{Methods}

This population-based study has a combination of longitudinal and cross-sectional design. In total, this study was conducted on 2086 healthy children (1029 boys and 1057 girls) who were born between 2002 and 2015 in Isfahan city, central Iran. Isfahan is the third largest city of Iran with a population of 2,250,000 based on the last census in 2017. The current study samples were selected from urban health centers of Isfahan through stratified by gender and multistage cluster sampling, among children who had medical records in the centers. Isfahan city has 2 main health centers, i.e., the Isfahan focal health centers I and II that cover the whole city. We adopted the WHO protocol for selecting our study sample from 2 main clusters and local health centers that were supervised $[6,18]$. Local health centers under the supervision of 2 local health centers are located in different geographic regions of Isfahan city. Isfahan health center I covers 23 health centers, and Isfahan health center II covers 22 health centers. We selected randomly 15 local health centers as the second-stage cluster based on considering the geographic coverage of the city for getting a representative sample. In each selected local health center, we provided a list of children that fulfilled the WHO criteria for constructing reference charts, and finally, we selected our proposed sample based on a systematic random sampling from prepared lists. In accordance with the WHO's instructions [6, 18], the inclusion criteria were as follows: Iranian citizenship, absence of significant morbidity or disease, lack of known health or environmental constraints to growth, appropriate socioeconomic status of the family, single and full-term birth, no maternal smoking before and after delivery, exclusive or predominant breastfeeding for at least 4 months, introduction of complementary foods by the age of 4-6 months, and continued partial breastfeeding up to at least 12 months. Then, according to a prepared list in each center, the longitudinal part of the study was conducted among children who had complete data on anthropometric measures in their medical charts and fully followed up from birth to 60 months in the health centers. Totally, 1325 healthy children who were born between 2002 and 2015 were identified and fulfilled our inclusion criteria, and their anthropometric measurements (at least 2 measurements) were recorded from medical records. For these children, data from 24 to 60 months were used for statistical analysis. For providing a sufficient sample size in order to have stable and precise estimates at the percentiles according to WHO recommendation for growth chart building, we conducted a cross-sectional study too, on 761 children aged 24-60 months from September 1 to November 10, 2015, and measured their weight and height. For conducting a cross-sectional study, a random telephone survey was done and contacted households who had medical charts in health centers, explained the purposes of the study, then invited them to participate in our study. Those parents who agreed to participate in the study were invited to measure the anthropometric measurements of their children by professional health staff in the health centers. All parents received enough information about the study and also provided written informed consent. The confidentiality of all obtained information was 
administered carefully by two reliable experts in each health center and also researchers of the study in each component of the study. The design of the current study was approved by the Ethics Committee of our University (Project Number: 193121).

\section{Anthropometric measurements}

Anthropometric measures (length/height and weight) of children were measured by trained health staff by using calibrated instruments under standard protocols in each component of the study $[6,18]$. The children's height in centimeters was measured in a supine position before walking and then in a standing position without shoes by using a tape meter with a precision of $0.1 \mathrm{~cm}$. Children's weight in kilograms was measured with a precision of $10 \mathrm{~g}$ on an electronic scale that was placed on flat ground, and participants were motionless and wearing light clothing. In the cross-sectional component, measurements were taken by two professional health staff in order to increase accuracy. Body mass index (BMI) was calculated as weight in kilograms $(\mathrm{kg})$ divided by height in meters squared $\left(\mathrm{m}^{2}\right)$.

\section{Statistical analysis}

We used the lambda-mu-sigma (LMS) method to develop new growth references for both boys and girls from 24 to 60 months. We supposed that data could be corrected for skewness by using an appropriate power transformation $(L)$, and the distribution was summarized by the median $(M)$ and generalized coefficient of variation $(S)$. The LMS method is used to model the data, smooth the parameters $(L, M$, and $S$ ), and then estimate the smoothed percentiles from the model parameters $[6,18,19]$. The model parameters were estimated based on the method of maximum penalized likelihood. Percentiles for all the anthropometric measures were estimated from those values applying the following formula [19]:

$$
P=M[1+L S Z]^{1 / L}, L \neq 0
$$

where the $L, M$, and $S$ are the values from the appropriate table corresponding to the age in months of the child. $Z$ is the $z$-score that corresponds to the percentile. $z$-scores correspond exactly to the percentiles, e.g., $z$ scores of $-1.881,-1.645,-1.282,-0.674,0,0.674$, $1.036,1.282,1.645$, and 1.881 correspond to the 3rd, 5th, 10th, 25th, 50th, 75th, 85th, 90th, 95th, and $97^{\text {th }}$ percentiles, respectively [19]. The goodness of fit of all models was assessed using the worm plot and $Q$ test $[6,18,19]$. We have estimated the 3rd, 5th, 15th, 50th, 85th, 90th, 95th, and 97th percentiles for height-for-age, weight-forage, and BMI-for-age. Data analysis was performed using the LMS Chart Maker Light, version 2.54.

\section{Results}

About $50.67 \%$ of the total studied children were girls and $63 \%$ of them were the first child of their family; $64.5 \%$ of fathers and $73.3 \%$ of mothers had a college education. About $37 \%$ of mothers were employed. Delivery by cesarean section was estimated to be $76.2 \%$. The mean (SD) age of mothers and fathers was 33.25 (6.73) and 38.01 (5.24) years, respectively. The mean (SD) gestational age of the Isfahan children was 38.38 (1.40) weeks. More details about the characteristics of the children and their parents are presented in Table 1.

Figures 1, 2, and 3 present the growth reference charts of Isfahan children aged 2-5 years at the 3rd, 5th, 15th, 50th, 85th, 90th, 95th, and 97th percentiles for heightfor-age, weight-for-age, and BMI-for-age for both girls and boys and the WHO growth standards counterparts. Tables 2, 3 and 4 present the percentiles for height-forage, weight-for-age, and BMI-for-age for both girls and boys from 24 to 60 months.

\section{Height-for-age}

The median height at birth, 30, 36, 42, 48, 54, and 60 months was 87.02, 90.90, 95.85, 99.66, 103.77, 106.77, and $110.52 \mathrm{~cm}$, respectively, for girls while for boys was 87.95, 91.99, 96.52, 100.42, 104.51, 107.96, and 111.48 $\mathrm{cm}$. Boys were taller than girls of the same age in all percentiles (Table 2).

Figure 1 compares the percentiles (P3, P15, P50, P85, and P97) of the Isfahan child growth references for height by age for girls and boys and the WHO growth standards. Differences in the percentiles of height between the Isfahan references and the WHO standards tended to increase with age for boys. Similar differences were observed for girls in the middle and upper percentiles. Compared with WHO standards, Isfahan boys were taller especially at older ages. Approximately, all percentile values of the height distribution were bigger than the WHO standards except the 3rd percentile, and the differences between the two growth references were about $2 \mathrm{~cm}$, especially at older ages. As depicted in Fig. 1, the differences between the 3rd and 97th percentiles for height increased with increasing age in both girls and boys in both growth references.

\section{Weight-for-age}

Median weight at birth, 30, 36, 42, 48, 54, and 60 months was $11.34,12.3,13.29,14.31,15.47,16.35$, and $17.48 \mathrm{~kg}$, respectively, for girls while for boys was 11.97, 12.94, $13.89,14.94,15.98,17.29$, and $18.19 \mathrm{~kg}$ (Table 3). Both the girls' and boys' weight increased with age, and as it was expected, boys were heavier than girls of the same age in over the all percentiles, with differences ranging from 0.1 to nearly $1 \mathrm{~kg}$. 
Table 1 Characteristics of studied participants

\begin{tabular}{|c|c|}
\hline Characteristics & $\begin{array}{l}\text { Percentage or mean } \\
\text { (SD) }\end{array}$ \\
\hline \multicolumn{2}{|l|}{ Delivery route } \\
\hline Natural & $23.8 \%$ \\
\hline Caesarean & $76.2 \%$ \\
\hline \multicolumn{2}{|l|}{ Birth order } \\
\hline 1 & $63 \%$ \\
\hline 2 & $32.2 \%$ \\
\hline$\geq 3$ & $4.9 \%$ \\
\hline \multicolumn{2}{|l|}{ Father's education } \\
\hline Under diploma & $2.7 \%$ \\
\hline Diploma & $32.8 \%$ \\
\hline University graduate & $64.5 \%$ \\
\hline \multicolumn{2}{|l|}{ Mother's education } \\
\hline Under diploma & $2.2 \%$ \\
\hline Diploma & $24.4 \%$ \\
\hline University graduate & $73.4 \%$ \\
\hline \multicolumn{2}{|l|}{ Father's employment } \\
\hline Private business & $36.9 \%$ \\
\hline Worker & $1.5 \%$ \\
\hline Administrative employee & $44.3 \%$ \\
\hline Master in university & $3.7 \%$ \\
\hline Other occupations & $13.6 \%$ \\
\hline \multicolumn{2}{|l|}{ Mother's employment } \\
\hline Housekeeper & $63 \%$ \\
\hline Private business & $3 \%$ \\
\hline Administrative employee & $22 \%$ \\
\hline Master in university & $3.7 \%$ \\
\hline Other occupations & $8.3 \%$ \\
\hline \multicolumn{2}{|l|}{ Number of mother's deliveries } \\
\hline 1 & $47.3 \%$ \\
\hline 2 & $44.8 \%$ \\
\hline$\geq 3$ & $7.9 \%$ \\
\hline Father's age (years) & $37.0(5.24)$ \\
\hline Mother's age (years) & $33.24(6.73)$ \\
\hline $\begin{array}{l}\text { Father's age at the birthdate of the child } \\
\text { (years) }\end{array}$ & $33.40(5.09)$ \\
\hline $\begin{array}{l}\text { Mother's age at the birthdate of the child } \\
\text { (years) }\end{array}$ & $28.84(4.21)$ \\
\hline Mother's height (cm) & $161.75(5.68)$ \\
\hline Mother's weight (kg) & $64.51(10.20)$ \\
\hline
\end{tabular}

As shown in Fig. 2, the weight patterns of Isfahan children were close to those of the WHO references in the lower percentiles. However, compared with WHO standards, Isfahan children especially girls were lighter based on the middle and upper percentiles of the weight distribution. Differences between the two growth references in the middle and upper percentiles were about 1 $\mathrm{kg}$, especially at 50 months of age and older. Similar to those we observed for height, the differences between the 3rd and 97th percentiles for weight increased with age in both girls and boys in each of the two growth references.

\section{BMI-for-age}

Median BMI at birth, 30, 36, 42, 48, 54, and 60 months was $15.04,14.94,14.55,14.54,14.50,14.50$, and 14.39 $\mathrm{kg} / \mathrm{m}^{2}$, respectively, for girls while for boys was 15.48 , $15.29,14.89,14.85,14.67,14.83$, and $14.65 \mathrm{~kg} / \mathrm{m}^{2}$ (Table 4). Boys had higher BMIs than girls of the same age in each group, with differences ranging from 0.1 to nearly $0.44 \mathrm{~kg} / \mathrm{m}^{2}$.

Figure 3 compares the percentiles (P3, P15, P50, P85, and P97) of the Isfahan child growth references for BMI by age for girls and boys and the WHO growth standards. Compared with the WHO standards (Fig. 3), Isfahan references exhibited lower BMI values across all age groups, with the exception of Isfahan boys at 55 to 58 months. Differences between the two growth references ranged from 0.2 to nearly $0.91 \mathrm{~kg} / \mathrm{m}^{2}$.

\section{Discussion}

We developed growth reference charts for height-, weight-, and BMI-for-age based on a representative sample of children aged 2-5 years who were born in Isfahan city, central Iran. According to our findings, the height, weight, and BMI percentile values for boys were higher than those for girls in all age groups. Compared with the WHO standards, Isfahan children had similar patterns of weight growth in the lower percentiles, but were lighter based on the middle and upper percentiles of the weight distribution. In addition, Isfahan boys were taller especially at older ages compared with WHO standards. The percentiles of the BMI distribution were considerably lower than those of WHO standards across all age groups. We adopted WHO guidelines for constructing the growth reference charts $[6,18]$; consequently, the prevalence rate of low birth weight $(<2500 \mathrm{~g})$ was $5.5 \%$ for Isfahan children.

The patterns of Isfahan children's weight growth showed similarity with those of the WHO standards only in the lower percentiles. However, the middle and upper percentiles of the weight distribution of Isfahan children especially girls were below the WHO standard curves. In line with our study, in Payande et al.'s study, the weight growth curves of Iranian children were below the WHO curves for children after 2 years [20].

Isfahan girls demonstrated patterns of height growth similar to those of the WHO standards in the middle and lower percentiles. However, compared with WHO 


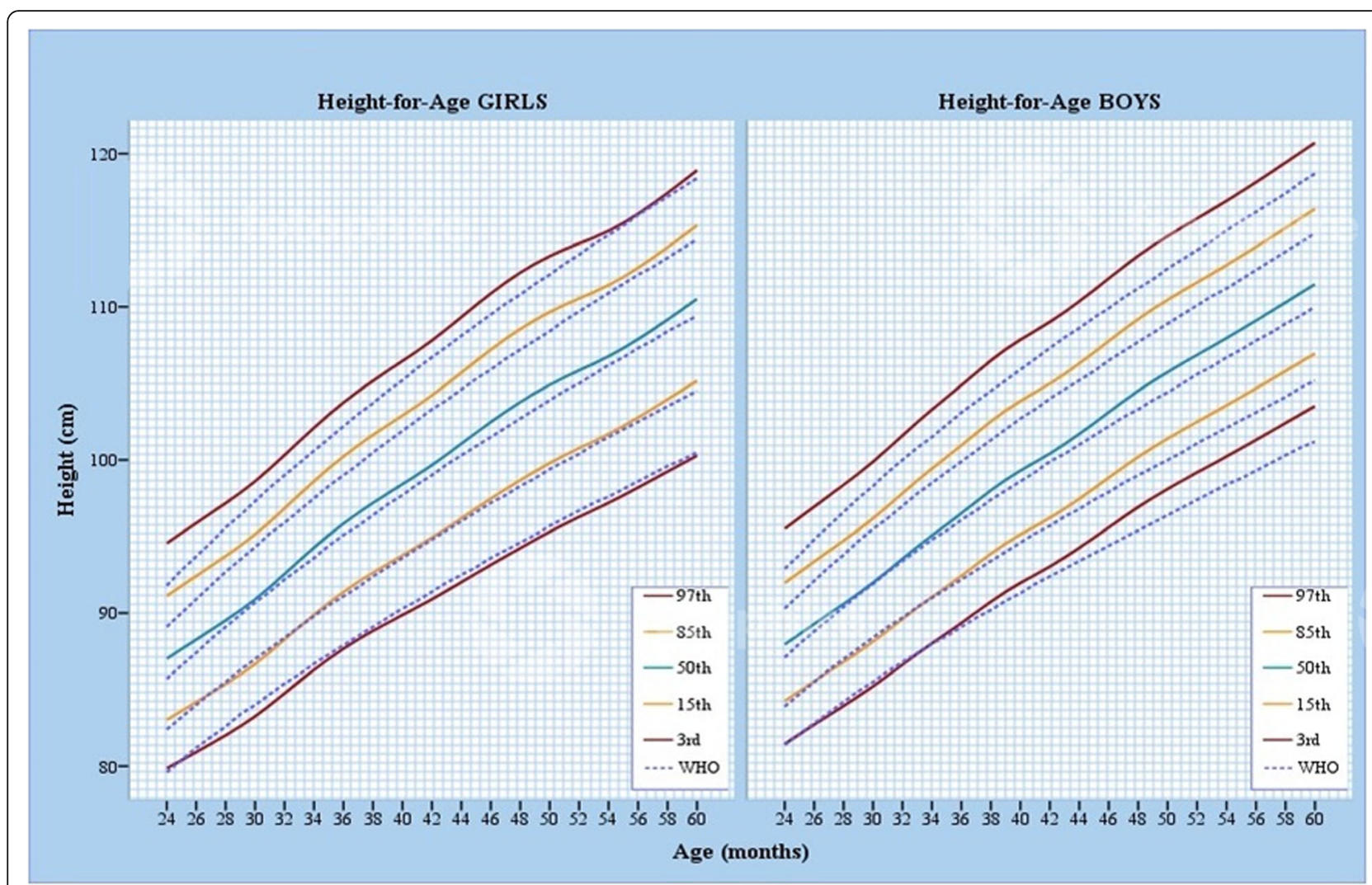

Fig. 1 Height percentiles (P3, P15, P50, P85, and P97) by age for girls and boys ages 2-5 years who were born in Isfahan compared to the WHO growth standards

standards, Isfahan boys were taller especially at older ages. Different previous studies in different countries found that growth charts differed from the WHO growth standards with regard to the height of children. For example, the results from WHO sample children were taller than the CDC and Japanese child population, and it is expected to obtain higher prevalence stunting $(<-2 \mathrm{SD})$ of if WHO references are used; however, in the population of China, Poland, and Germany, the cutoff value for depicting stunting were higher than those reported values by $\mathrm{WHO}$, resulting in the underestimate of stunting prevalence in these nations when WHO references are applied [21-24]. According to the observed difference between our study results in terms of heightfor-age and the higher centiles of our study than corresponding WHO, it is expected to have underestimates of stunting for our local population by applying WHO references. Such differences in various studies have been attributed to variations in the inclusion criteria for included children, ethnicity, and sample sizes, environmental and nutritional factors have caused the divergence in growth patterns.

BMI growth curves demonstrated by Isfahan children did not follow the WHO standards. Hosseini et al. conducted a survey among 3301 children aged 2-18 years old between 1990 and 1991 in order to provide standardized percentile curves of BMI for Iranian children [25]. Their reference had some weak points including they measured the age based on years not on months, so a child aged 2 years and 1 day was considered such as a child aged 2 years and 11 months, and children resident in Tehran cannot represent the children of Iran. However, in line with our findings, the major differences were observed between Iranian and the US BMI charts in their study [25].

These findings showed that the WHO standards are high for identification of the growth and nutritional status of an Iranian child relative to its compatriots. Studies in other countries have achieved similar results in terms of the need for local child growth references [2, 4, 2629]; for example, Al-Mazrou et al.'s study showed that the median weights and heights of Saudi boys and girls $(0-5$ years old) were more than those of Harvard standards [26]. Findings regarding the difference between our references and WHO standards in terms of these indices suggest that the prevalence of growth deficiency in this local population will be higher if assessed by the WHO standards. Therefore, these results reflect the imprecision and inapplicability of the international references such as WHO and CDC reference and support the 




Fig. 2 Weight percentiles (P3, P15, P50, P85, and P97) by age for girls and boys ages $2-5$ years who were born in Isfahan compared to the WHO growth standards



Fig. 3 BMl percentiles (P3, P15, P50, P85, and P97) by age for girls and boys ages 2-5 years who were born in Isfahan compared to the WHO growth standards 
Table 2 Percentiles of height (cm)-for-age for girls and boys, age in months

\begin{tabular}{|c|c|c|c|c|c|c|c|c|c|c|c|c|c|c|c|c|}
\hline \multirow{2}{*}{$\begin{array}{l}\text { Age } \\
\text { (months) }\end{array}$} & \multicolumn{8}{|l|}{ Girls } & \multicolumn{8}{|l|}{ Boys } \\
\hline & $3 r d$ & 5th & 15th & 50th & 85th & 90th & 95th & 97th & $3 \mathrm{rd}$ & 5th & 15th & 50th & 85th & 90th & 95th & 97th \\
\hline 24 & 79.85 & 80.73 & 83.03 & 87.02 & 91.13 & 92.12 & 93.59 & 94.56 & 81.46 & 82.22 & 84.25 & 87.95 & 91.97 & 92.97 & 94.49 & 95.51 \\
\hline 25 & 80.39 & 81.28 & 83.61 & 87.64 & 0178 & 92.77 & 125 & .22 & .09 & 82.86 & 4.90 & 88.62 & 2.66 & 93.67 & 5.21 & 6.23 \\
\hline 26 & 80.92 & 81.83 & 84.19 & 88.27 & 92.43 & 93.42 & 94.91 & 95.88 & 82.71 & 83.49 & 85.54 & 89.28 & 93.35 & 94.37 & 95.91 & 96.94 \\
\hline 27 & 1.46 & 82.38 & 84.77 & 88.89 & 93.07 & 94.07 & 95.56 & 96.53 & 83.33 & 84.11 & 86.18 & 89.95 & 94.04 & 95.07 & 96.62 & 97.66 \\
\hline 28 & 82.02 & 82.95 & 85.36 & 89.52 & 93.72 & 94.12 & 90.21 & 97.18 & 3.94 & 84.73 & 86.81 & 90.61 & 94.73 & 95.76 & 97.33 & 98.37 \\
\hline 29 & 82.61 & 83.55 & 85.99 & 90.18 & 94.40 & 95.40 & 96.89 & 97.86 & 84.57 & 85.35 & 87.46 & 91.28 & 95.44 & 96.47 & 98.05 & 99.10 \\
\hline 30 & .26 & 84.21 & 86.68 & 90.90 & 95.14 & 96.14 & 97.63 & 98.60 & 22 & 8 & 8 & 91.99 & 18 & 97.23 & 98.82 & 99.88 \\
\hline 31 & 83.98 & 84.95 & 87.45 & 91.70 & 95.96 & 96.97 & 98.46 & 99.43 & 85.92 & 86.72 & 88.86 & 92.75 & 96.99 & 98.05 & 99.65 & 100.72 \\
\hline 32 & 5 & 8 & 88.26 & 92. & 90. & 97.85 & s & 2 & 86.63 & 8 & 8 & 9 & 9 & 98.89 & 52 & $\pi$ \\
\hline 33 & 85.54 & 86.53 & 89.09 & 93.43 & 97.73 & 98.75 & 100.25 & 101.22 & 87.34 & 88.16 & 90.35 & 94.32 & 98.65 & 99.72 & 101.37 & 102.46 \\
\hline 34 & .29 & 87.31 & 89.90 & 94.28 & 98.61 & 99.63 & 101.13 & 102.10 & 8.02 & 88.85 & 91.05 & 95.06 & 99.43 & 100.52 & 102.18 & 103.28 \\
\hline 35 & 87.01 & 88.04 & 90.67 & 95.09 & 99.44 & 100.47 & 101.97 & 102.95 & 88.68 & 89.52 & 91.74 & 95.79 & 100.19 & 101.29 & 102.96 & 104.08 \\
\hline 36 & 87.68 & 88.72 & 9 & 95.85 & 3 & 5 & 2.77 & 5 & 5 & 90.20 & g & 96.52 & 96 & 102.07 & 75 & 4.88 \\
\hline 37 & 3.28 & 89.34 & 92.04 & 96.54 & 100.95 & 101.98 & 103.50 & 8 & (.05 & 90.90 & 93 & 97.27 & 74 & 102.86 & 56 & 1 \\
\hline 38 & 88.84 & 89.91 & 92.64 & 97.19 & 101.63 & 102.66 & 104.19 & 105.17 & 90.75 & 91.60 & 93.88 & 98.01 & 102.51 & 103.64 & 105.35 & 106.49 \\
\hline 39 & 36 & 9 & 9 & 97.81 & 102 & 3.31 & 104.84 & 5.82 & .40 & 9 & 94 & 98. & 22 & 104.35 & 106.07 & 107.22 \\
\hline 40 & 89.87 & 90.97 & 93.77 & 98.41 & 102.90 & 103.94 & 105.47 & 106.46 & 91.97 & 92.83 & 95.13 & 99.30 & 103.84 & 104.97 & 106.70 & 107.85 \\
\hline 41 & 90.38 & 0 & 94.34 & 99.02 & 4 & 8 & 2 & 0 & 92.50 & 93.37 & 0 & 985 & 1 & 105.54 & 27 & 42 \\
\hline 42 & 90.90 & 92.04 & 94.92 & 99.66 & 104.21 & 105.26 & 106.80 & 107.79 & 93.04 & 93.91 & 96.22 & 100.42 & 104.98 & 106.12 & 107.85 & 109.01 \\
\hline 13 & 91.46 & 92.62 & 95.55 & 100.35 & 104.94 & 106.00 & 107.54 & 108.54 & 93.63 & 94.50 & 96.82 & 101.03 & 105.61 & 106.76 & 108.50 & 109.65 \\
\hline 14 & 92.02 & 93.21 & 96.19 & 101.06 & 105.70 & 106.76 & 108.32 & 109.32 & 94.20 & 95.14 & 97.46 & 101.70 & 106.30 & 107.45 & 109.19 & 110.35 \\
\hline 45 & 92.59 & 93.80 & 96.84 & 101.78 & 106.46 & 107.53 & 109.10 & 110.11 & 94.92 & 95.80 & 98.14 & 102.40 & 107.02 & 108.17 & 109.93 & 111.09 \\
\hline 46 & 9 & 9 & 97 & 10 & 10 & 1 & 6 & 7 & 0 & 96.49 & 9 & 1 & 6 & 22 & 88 & 1 \\
\hline 47 & 93.70 & 94.95 & 98.08 & 103.14 & 107.90 & 108.99 & 110.57 & 111.58 & 96.28 & 97.17 & 99.53 & 103.83 & 108.50 & 109.66 & 111.43 & 112.61 \\
\hline 48 & 424 & 95.51 & 98.68 & 103.77 & 108.55 & 109.63 & 111.22 & 112.23 & 0603 & 97.82 & 100.20 & 104.51 & 109.20 & 110.37 & 112.15 & 113.33 \\
\hline 49 & 94.78 & 96.06 & 99.25 & 104.36 & 109.13 & 110.22 & 111.80 & 12.81 & 97.53 & 98.43 & 100.82 & 105.15 & 109.85 & 111.02 & 112.81 & 113.99 \\
\hline 6 & 5.31 & 96.59 & 99.79 & 104.90 & 109.65 & 110.73 & 112.30 & 113.31 & 98.10 & 99.00 & 101.40 & 105.74 & 110.46 & 111.63 & 113.42 & 114.61 \\
\hline כ1 & 5.81 & 97.10 & 100.30 & 105.39 & 2 & 9 & 5 & 4 & 98.65 & 9 & 5 & 10 & 4 & 21 & 01 & 1 \\
\hline 52 & 96.28 & 97.57 & 100.77 & 105.85 & 110.55 & 111.61 & 113.15 & 114.14 & 99.18 & 100.08 & 102.49 & 106.86 & 111.60 & 112.78 & 114.57 & 115.77 \\
\hline & 6.74 & 98.03 & 101.23 & 106.29 & 110.96 & 112.02 & 113.55 & 4.52 & 70 & 100.61 & 2 & 0 & 6 & 4 & 14 & 1 \\
\hline 54 & 97.20 & 98.50 & 101.70 & 106.77 & 111.42 & 112.47 & 113.99 & 114.96 & 100.23 & 101.14 & 103.56 & 107.96 & 112.72 & 113.91 & 115.72 & 116.92 \\
\hline 55 & 97.69 & 98.99 & 102.22 & 107.30 & 111.95 & 112.99 & 114.51 & 115.47 & 100.76 & 101.68 & 104.11 & 108.52 & 113.31 & 114.50 & 116.31 & 117.52 \\
\hline 56 & 98.20 & 99.52 & 102.77 & 107.88 & 112.54 & 113.59 & 115.11 & 116.07 & 101.31 & 102.23 & 104.67 & 109.10 & 113.91 & 115.11 & 116.93 & 118.14 \\
\hline 57 & 98.72 & 100.06 & 103.35 & 108.51 & 113.19 & 114.24 & 115.76 & 116.73 & 101.86 & 102.78 & 105.24 & 109.69 & 114.52 & 115.73 & 117.56 & 118.77 \\
\hline Do & 99.24 & 100.61 & 103.95 & 109.16 & 113.88 & 114.94 & 116.46 & 17.43 & 102.41 & 103.34 & 105.81 & 110.28 & 115.14 & 116.35 & 118.19 & 119.42 \\
\hline 59 & 99.76 & 101.16 & 104.56 & 109.84 & 114.60 & 115.66 & 117.19 & 118.17 & 102.96 & 103.89 & 106.38 & 110.88 & 115.77 & 116.98 & 118.84 & 120.07 \\
\hline 60 & 100.28 & 101.71 & 105.17 & 110.52 & 115.32 & 116.39 & 117.94 & 118.92 & 103.51 & 104.45 & 106.95 & 111.48 & 116.39 & 117.62 & 119.48 & 120.72 \\
\hline
\end{tabular}

need for local child growth references, in order to better monitor the growth and development of children in Isfahan and consequently in Iran. However, further research is necessary to investigate the weight and BMI growth trajectories of Iranian children and the determinants of said trajectories.
It is important to recognize some strengths as well as the potential limitations of the present study. This survey can be considered as the first study using a large sample of healthy child construct growth references for all anthropometric measures (weight, height, and BMI) for children aged 2-5 years prospectively in the largest 
Table 3 Percentiles of weight (kg)-for-age for girls and boys, age in months

\begin{tabular}{|c|c|c|c|c|c|c|c|c|c|c|c|c|c|c|c|c|}
\hline \multirow{2}{*}{$\begin{array}{l}\text { Age } \\
\text { (months) }\end{array}$} & \multicolumn{8}{|l|}{ Girls } & \multicolumn{8}{|l|}{ Boys } \\
\hline & $3 r d$ & 5th & 15th & 50th & 85th & 90th & 95th & 97th & $3 r d$ & 5th & 15th & 50th & 85th & 90th & 95th & 97th \\
\hline 24 & 9.31 & 9.52 & 10.11 & 11.34 & 12.98 & 13.45 & 14.22 & 14.78 & 9.89 & 10.11 & 10.73 & 11.97 & 13.51 & 13.93 & 14.61 & 15.08 \\
\hline 25 & 9.41 & 9.62 & 10.22 & 11.46 & 13.1 & 13.57 & 14.35 & 14.91 & 10.01 & 10.23 & 10.85 & 12.1 & 13.65 & 14.08 & 14.75 & 15.23 \\
\hline 26 & 9.52 & 9.73 & 10.33 & 11.58 & 13.24 & 13.71 & 14.49 & 15.05 & 10.13 & 10.35 & 10.98 & 12.24 & 13.8 & 14.23 & 14.91 & 15.39 \\
\hline 27 & 9.64 & 9.85 & 10.46 & 11.73 & 13.39 & 13.87 & 14.65 & 15.21 & 10.26 & 10.48 & 11.12 & 12.39 & 13.97 & 14.4 & 15.09 & 15.57 \\
\hline 28 & 9.78 & 10 & 10.62 & 11.9 & 13.58 & 14.06 & 14.85 & 15.41 & 10.4 & 10.63 & 11.27 & 12.56 & 14.16 & 14.6 & 15.3 & 15.79 \\
\hline 29 & 9.94 & 10.16 & 10.79 & 12.09 & 13.8 & 14.28 & 15.08 & 15.65 & 10.55 & 10.78 & 11.44 & 12.75 & 14.37 & 14.82 & 15.53 & 16.02 \\
\hline 30 & 10.11 & 10.33 & 10.97 & 12.3 & 14.03 & 14.52 & 15.33 & 15.91 & 10.7 & 10.94 & 11.61 & 12.94 & 14.6 & 15.05 & 15.78 & 16.28 \\
\hline 31 & 10.28 & 10.51 & 11.16 & 12.51 & 14.28 & 14.78 & 15.6 & 16.19 & 10.86 & 11.1 & 11.78 & 13.14 & 14.83 & 15.29 & 16.03 & 16.55 \\
\hline 32 & .44 & 10.68 & 11.35 & 12.72 & 14.52 & 15.03 & 15.87 & 16.47 & 11 & 11.24 & 11.94 & 13.32 & 15.05 & 15.52 & 16.28 & 16.81 \\
\hline 33 & 10.58 & 10.82 & 11.5 & 12.91 & 14.74 & 15.26 & 16.12 & 16.73 & 11.11 & 11.37 & 12.07 & 13.48 & 15.25 & 15.73 & 16.5 & 17.04 \\
\hline 34 & 10.69 & 10.94 & 11.63 & 13.06 & 14.93 & 15.46 & 16.33 & 16.95 & 11.21 & 11.46 & 12.18 & 13.61 & 15.41 & 15.9 & 16.69 & 17.24 \\
\hline 35 & 10.78 & 11.03 & 11.73 & 13.18 & 15.08 & 15.62 & 16.51 & 17.14 & 11.29 & 11.55 & 12.28 & 13.74 & 15.56 & 16.06 & 16.86 & 17.43 \\
\hline 36 & 10.85 & 11.1 & 11.82 & 13.29 & 15.23 & 15.78 & 16.68 & 17.32 & 11.4 & 11.66 & 12.4 & 13.89 & 15.75 & 16.26 & 17.07 & 17.65 \\
\hline 37 & 10.92 & 11.18 & 11.9 & 13.4 & 15.37 & 15.93 & 16.85 & 17.51 & 11.54 & 11.81 & 12.56 & 14.08 & 15.98 & 16.51 & 17.34 & 17.93 \\
\hline 38 & 11 & 11.26 & 12 & 13.53 & 15.53 & 16.11 & 17.04 & 17.71 & 11.7 & 11.97 & 12.75 & 14.3 & 16.25 & 16.78 & 17.64 & 18.25 \\
\hline 39 & 11.1 & 11.37 & 12.12 & 13.68 & 15.72 & 16.3 & 17.26 & 17.94 & 11.85 & 12.13 & 12.92 & 14.51 & 16.5 & 17.05 & 17.93 & 18.55 \\
\hline 40 & 11.24 & 11.51 & 12.27 & 13.86 & 15.95 & 16.54 & 17.51 & 18.21 & 11.98 & 12.27 & 13.07 & 14.68 & 16.72 & 17.28 & 18.17 & 18.8 \\
\hline 41 & 1 & 11 & 1 & 14.07 & 16.2 & 16 & 17 & 2 & 8 & 7 & 18 & 2 & 9 & 46 & 18 & 01 \\
\hline 42 & 11.57 & 11.85 & 12.65 & 14.31 & 16.48 & 17.1 & 18.12 & 18.85 & 12.16 & 12.45 & 13.27 & 14.94 & 17.03 & 17.61 & 18.54 & 19.19 \\
\hline 43 & 11.76 & 12.04 & 12.86 & 14.55 & 16.78 & 17.41 & 18.45 & 19.19 & 12.21 & 12.51 & 13.34 & 15.03 & 17.15 & 17.74 & 18.68 & 19.34 \\
\hline 44 & 11.94 & 12.23 & 13.07 & 14.79 & 17.07 & 17.71 & 18.77 & 19.53 & 12.28 & 12.58 & 13.42 & 15.13 & 17.28 & 17.88 & 18.84 & 19.51 \\
\hline 45 & 12.1 & 12.4 & 13.25 & 15.01 & 17.33 & 17.98 & 19.06 & 19.83 & 12.38 & 12.69 & 13.54 & 15.28 & 17.47 & 18.07 & 19.05 & 19.73 \\
\hline 46 & 12 & 12 & 13.4 & 15 & 17.54 & 18 & 19 & 2 & 1. & 5 & 2 & 1 & 3 & 4 & 4 & 03 \\
\hline 47 & 12.34 & 12.65 & 13.53 & 15.34 & 17.72 & 18.4 & 19.51 & 20.3 & 12.73 & 13.05 & 13.94 & 15.74 & 18.02 & 18.65 & 19.67 & 20.38 \\
\hline 48 & 12.44 & 12.75 & 13.64 & 15.47 & 17.88 & 18.57 & 19.69 & 20.49 & 12.92 & 13.24 & 14.15 & 15.98 & 18.31 & 18.95 & 19.99 & 20.72 \\
\hline 49 & 12.53 & 12.85 & 13.75 & 15.6 & 18.04 & 18.73 & 19.86 & 20.67 & 13.07 & 13.4 & 14.32 & 16.19 & 18.55 & 19.21 & 20.26 & 21 \\
\hline 50 & 12.63 & 12.95 & 13.86 & 15.74 & 18.2 & 18.89 & 20.03 & 20.84 & 13.2 & 13.54 & 14.47 & 16.37 & 18.77 & 19.43 & 20.5 & 21.26 \\
\hline 51 & 12.73 & 13.05 & 13.97 & 15.87 & 18.36 & 19.06 & 20.21 & 21.03 & 13.35 & 13.68 & 14.63 & 16.56 & 19 & 19.68 & 20.76 & 21 \\
\hline 52 & 12.83 & 13.16 & 14.09 & 16.02 & 18.53 & 19.25 & 20.41 & 21.24 & 13.51 & 13.86 & 14.83 & 16.79 & 19.28 & 19.97 & 21.07 & 21.85 \\
\hline 53 & 12.94 & 13.28 & 14.22 & 16.18 & 18.73 & 19.45 & 20.63 & 21.47 & 13.7 & 14.05 & 15.04 & 17.04 & 19.58 & 20.28 & 21.41 & 2.21 \\
\hline 54 & 13.07 & 13.4 & 14.37 & 16.35 & 18.94 & 19.68 & 20.87 & 21.73 & 13.88 & 14.24 & 15.25 & 17.29 & 19.88 & 20.6 & 21.76 & 22.57 \\
\hline 55 & 13.2 & 13.54 & 14.52 & 16.54 & 19.18 & 19.93 & 21.15 & 22.02 & 14.05 & 14.41 & 15.44 & 17.52 & 20.17 & 20.9 & 22.08 & 22.92 \\
\hline 56 & 13.33 & 13.68 & 14.68 & 16.74 & 19.44 & 20.2 & 21.45 & 22.34 & 14.19 & 14.56 & 15.6 & 17.72 & 20.42 & 21.17 & 22.38 & 23.23 \\
\hline 57 & 13.46 & 13.82 & 14.83 & 16.94 & 19.69 & 20.47 & 21.75 & 22.66 & 14.3 & 14.68 & 15.73 & 17.89 & 20.63 & 21.4 & 22.63 & 23.5 \\
\hline 58 & 13.57 & 13.94 & 14.98 & 17.12 & 19.94 & 20.74 & 22.04 & 22.97 & 14.37 & 14.76 & 15.83 & 18.01 & 20.8 & 21.58 & 22.83 & 23.71 \\
\hline 59 & 13.68 & 14.05 & 15.11 & 17.3 & 20.18 & 21 & 22.33 & 23.28 & 14.43 & 14.81 & 15.9 & 18.11 & 20.94 & 21.73 & 23 & 23.9 \\
\hline 60 & 13.78 & 14.16 & 15.24 & 17.48 & 20.42 & 21.26 & 22.62 & 23.59 & 14.46 & 14.85 & 15.95 & 18.19 & 21.06 & 21.86 & 23.15 & 24.06 \\
\hline
\end{tabular}

city of Iran as a representative of center Iran population. We followed the standards and reliable international protocols; the suggested large sample size with 400 to 500 observations in each age-gender group allows the calculation of stable and precise estimates at the percentiles [30]. Most of the previous studies in Iran were based on a low sample size or they did not consider all the three anthropometric measures, simultaneously. We constructed the references for children aged 24-60 months based on WHO's inclusion criteria; therefore, the Isfahan references and WHO standards were completely comparable. The LMS methodology used in this 
Table 4 Percentiles of BMI $\left(\mathrm{kg} / \mathrm{m}^{2}\right)$-for-age for girls and boys, age in months

\begin{tabular}{|c|c|c|c|c|c|c|c|c|c|c|c|c|c|c|c|c|}
\hline \multirow{2}{*}{$\begin{array}{l}\text { Age } \\
\text { (months) }\end{array}$} & \multicolumn{8}{|l|}{ Girls } & \multicolumn{8}{|l|}{ Boys } \\
\hline & $3 r d$ & 5th & 15th & 50th & 85th & 90th & 95th & 97th & $3 r d$ & 5th & 15th & 50th & 85th & 90th & 95th & 97th \\
\hline 24 & 12.93 & 13.16 & 13.79 & 15.04 & 16.57 & 16.98 & 17.64 & 18.09 & 13.34 & 13.57 & 14.22 & 15.48 & 17.01 & 17.42 & 18.06 & 18.51 \\
\hline 25 & 2.93 & 13.16 & 13.79 & 15.02 & 16.54 & 16.95 & 17.60 & 18.05 & 31 & 13.54 & 14.18 & 15.44 & 16.96 & 17.36 & 18.01 & 18.45 \\
\hline 26 & 12.93 & 13.15 & 13.78 & 15.01 & 16.51 & 16.92 & 17.56 & 18.00 & 13.28 & 13.51 & 14.15 & 15.40 & 16.91 & 17.32 & 17.96 & 18.40 \\
\hline 27 & 12.93 & 13.15 & 13.77 & 15.00 & 16.49 & 16.89 & 17.52 & 17.97 & 13.26 & 13.49 & 14.13 & 15.37 & 16.88 & 17.28 & 17.92 & 18.36 \\
\hline 28 & 12.93 & 13.15 & 13.77 & 14.98 & 16.47 & 16.86 & 17.50 & 17.93 & 13.24 & 13.47 & 14.11 & 15.35 & 16.85 & 17.25 & 17.89 & 18.33 \\
\hline 29 & 12.92 & 13.14 & 13.76 & 14.97 & 16.44 & 16.84 & 17.47 & 17.90 & 13.22 & 13.45 & 14.09 & 15.33 & 16.83 & 17.23 & 17.86 & 18.30 \\
\hline 30 & .90 & 13.12 & 13.73 & 14.94 & 16.41 & 16.80 & 17.43 & 17.86 & 1 & 13 & 14.05 & 15 & 16 & 17.19 & 17.82 & 18.26 \\
\hline 31 & 12.86 & 13.08 & 13.69 & 14.89 & 16.36 & 16.75 & 17.38 & 17.81 & 13.13 & 13.36 & 14.00 & 15.23 & 16.72 & 17.12 & 17.75 & 18.19 \\
\hline 32 & .80 & 13.02 & 13.63 & 14.83 & 16.29 & 16.69 & 17.3 & 17.74 & 13.06 & 13.29 & 13.92 & 15 & 16. & 17.05 & 17.68 & 18.11 \\
\hline 33 & 12.73 & 12.95 & 13.56 & 14.76 & 16.22 & 16.61 & 17.24 & 17.67 & 12.99 & 13.22 & 13.85 & 15.08 & 16.57 & 16.96 & 17.59 & 18.03 \\
\hline 34 & 12.66 & 12.88 & 13.49 & 14.68 & 16.14 & 16.54 & 17.16 & 17.60 & 12.92 & 13.15 & 13.78 & 15.01 & 16.49 & 16.89 & 17.52 & 17.96 \\
\hline 35 & 12.58 & 12.80 & 13.41 & 14.61 & 16.07 & 16.47 & 17.09 & 17.53 & 12.86 & 13.09 & 13.72 & 14.95 & 16.43 & 16.83 & 17.46 & 17.90 \\
\hline 36 & 12.52 & 12.74 & 13.35 & 14.55 & 16.02 & 16.41 & 17.04 & 17.48 & 12.81 & 13.04 & 13.67 & 14.89 & 16.38 & 16.78 & 17.41 & 17.85 \\
\hline 37 & 12.48 & 12.70 & 13.31 & 14.51 & 15.99 & 16.38 & 17.01 & 17.45 & 12.77 & 13.00 & 13.63 & 14.86 & 16.35 & 16.75 & 17.38 & 17.82 \\
\hline 38 & 12.45 & 12.67 & 13.29 & 14.50 & 15.97 & 16.38 & 17.01 & 17.45 & 12.75 & 12.98 & 13.60 & 14.83 & 16.32 & 16.72 & 17.36 & 17.80 \\
\hline 39 & 12.44 & 12.66 & 13.28 & 14.49 & 15.98 & 16.39 & 17.03 & 17.47 & 12.74 & 12.97 & 13.60 & 14.8 & 16.32 & 16.72 & 17.36 & 17.79 \\
\hline 40 & 12.44 & 12.66 & 13.28 & 14.51 & 16.01 & 16.41 & 17.06 & 17.51 & 12.75 & 12.98 & 13.60 & 14.84 & 16.33 & 16.73 & 17.37 & 17.81 \\
\hline 41 & 5 & 1. & 9 & D & 4 & 5 & 0 & 5 & 6 & 9 & D & 5 & 16.35 & 5 & 9 & 83 \\
\hline 42 & 12.45 & 12.68 & 13.30 & 14.54 & 16.07 & 16.49 & 17.15 & 17.61 & 12.76 & 12.99 & 13.62 & 14.85 & 16.35 & 16.76 & 17.39 & 17.84 \\
\hline 43 & 12.45 & 12.68 & 13.31 & 14.56 & 16.10 & 16.52 & 17.19 & 17.66 & 12.74 & 12.97 & 13.60 & 14.83 & 16.33 & 16.73 & 17.37 & 17.81 \\
\hline 44 & 12.44 & 12.67 & 13.30 & 14.57 & 16.12 & 16.55 & 17.22 & 17.69 & 12.70 & 12.93 & 13.56 & 14.79 & 16.29 & 16.70 & 17.33 & 17.78 \\
\hline 45 & 12.42 & 12.65 & 13.29 & 14.56 & 16.13 & 16.56 & 17.24 & 17.72 & 12.66 & 12.89 & 13.52 & 14.75 & 16.25 & 16.65 & 17.29 & 17.73 \\
\hline 46 & 12.40 & 12.63 & 13.27 & 14.55 & 16.13 & 16.56 & 17 & 17 & 12.63 & 12.85 & 13.48 & 14 & 16 & 16. & 17 & 17 \\
\hline 47 & 12.37 & 12.60 & 13.24 & 14.53 & 16.12 & 16.55 & 17.25 & 17.74 & 12.59 & 12.82 & 13.45 & 14.68 & 16.19 & 16.59 & 17.23 & 17.67 \\
\hline 48 & 12.33 & 12.56 & 13.21 & 14.50 & 16.10 & 16.54 & 17.24 & 17.73 & 12.57 & 12.80 & 13.43 & 14.67 & 16.17 & 16.57 & 17.22 & 17. \\
\hline 49 & 12.29 & 12.53 & 13.18 & 14.47 & 16.08 & 16.52 & 17.22 & 17.72 & 12.56 & 12.79 & 13.42 & 14.66 & 16.17 & 16.57 & 17.22 & 17.66 \\
\hline 50 & 12.27 & 12.50 & 13.15 & 14.45 & 16.06 & 16.51 & 17.21 & 17.71 & 12.56 & 12.79 & 13.42 & 14.66 & 16.18 & 16.59 & 17.24 & 17.69 \\
\hline 51 & 2.20 & 12.49 & 13.14 & 14.44 & 16.06 & 16.51 & 17.2 & 17.72 & 12.57 & 12.80 & 13. & 14. & 16 & 16. & 17 & 17 \\
\hline 52 & 12.25 & 12.49 & 13.14 & 14.45 & 16.09 & 16.54 & 17.25 & 17.76 & 12.60 & 12.83 & 13.47 & 14.73 & 16.27 & 16.69 & 17.35 & 17.80 \\
\hline 53 & 12.27 & 12.50 & 13.16 & 14.48 & 16.13 & 16.58 & 17.30 & 17.81 & 12.63 & 12.87 & 13.51 & 14.78 & 16.34 & 16.76 & 17.42 & 17. \\
\hline 54 & 12.28 & 12.52 & 13.18 & 14.50 & 16.16 & 16.62 & 17.35 & 17.87 & 12.66 & 12.89 & 13.54 & 14.83 & 16.40 & 16.82 & 17.49 & 17.96 \\
\hline 55 & 12.28 & 12.52 & 13.18 & 14.52 & 16.19 & 16.65 & 17.39 & 17.91 & 12.66 & 12.90 & 13.55 & 14.85 & 16.43 & 16.86 & 17.55 & 18.02 \\
\hline 56 & 12.27 & 12.51 & 13.18 & 14.52 & 16.21 & 16.67 & 17.42 & 17.94 & 12.65 & 12.88 & 13.54 & 14.85 & 16.45 & 16.88 & 17.57 & 18.05 \\
\hline 57 & 12.24 & 12.48 & 13.16 & 14.51 & 16.21 & 16.68 & 17.43 & 17.96 & 12.61 & 12.85 & 13.51 & 14.82 & 16.44 & 16.88 & 17.58 & 18.06 \\
\hline 58 & 12.20 & 12.44 & 13.12 & 14.48 & 16.19 & 16.66 & 17.42 & 17.96 & 12.55 & 12.79 & 13.46 & 14.78 & 16.41 & 16.85 & 17.55 & 18.05 \\
\hline 59 & 12.15 & 12.40 & 13.07 & 14.44 & 16.16 & 16.64 & 17.40 & 17.94 & 12.48 & 12.72 & 13.39 & 14.72 & 16.36 & 16.80 & 17.51 & 18.01 \\
\hline 60 & 12.10 & 12.34 & 13.02 & 14.39 & 16.13 & 16.61 & 17.38 & 17.92 & 12.40 & 12.64 & 13.31 & 14.65 & 16.30 & 16.75 & 17.47 & 17.97 \\
\hline
\end{tabular}

study is the most common method by the WHO and the $\mathrm{CDC}$ and also other countries to construct children's growth references. Despite these strengths, the anthropometric data in the longitudinal component of the current study collected from the medical record of each child had been measured by professional health staff in the health centers. We included children only from Isfahan (in central Iran); therefore, the representativeness of this sample for all Iranian children is not known. On the other hand, we included only the urban population in this study, so our population will not be a true representativeness of the whole population of Iranian children. 


\section{Conclusion}

This study developed Isfahan growth references to monitor the growth of children between 2 and 5 years. These growth references are the most recent and comprehensive charts of the Isfahan population of children. The weight and BMI growth patterns of Isfahan children were different from those "prescribed" by WHO standards. These findings suggest that caution should be taken when applying the WHO standards to Iranian children. The accessibility of such reference charts should help clinicians and healthcare providers in the Isfahan to better monitor the children. Accordingly, we recommend these growth reference charts to be used by all health centers and hospitals of Isfahan city. Also, we strongly encourage further similar studies in the Iranian population to establish national growth reference charts.

\section{Abbreviations}

BMI: Body mass index; CDC: Disease control and prevention; LMS: Lambdamu-sigma; WHO: World Health Organization

\section{Acknowledgements}

We are grateful to all persons who participated in our study. We also appreciate Mrs. Zamane Vafaei, Mr. Hosseingholi Najafi, Mrs. Marzieh Heidari, and the Vice Chancellor for Health and Isfahan Provincial Health Center and all the staff of Health Centers of Isfahan for their excellent cooperation.

\section{Authors' contributions}

$\mathrm{AF}$ and $\mathrm{ZH}$ contributed to the study design, data collection, data interpretation, and writing of the manuscript. RK contributed to the study design and revision of the manuscript. SR contributed to the data collection and prepared the data. All authors approved the final version of the manuscript.

\section{Funding}

The primary corresponding author (AF) of this study received funding from Isfahan University of Medical Sciences in order to conduct the study and collect the data.

\section{Availability of data and materials}

Data sharing is not applicable to this article.

\section{Ethics approval and consent to participate}

The design of the current study was approved by the Ethics Committee of Isfahan University of Medical Sciences (Project Number: 193121). All parents received enough information about the study and also provided written informed consent.

\section{Consent for publication}

Not applicable.

\section{Competing interests}

The authors declare that they have no competing interests.

\section{Author details}

'Department of Biostatistics and Epidemiology, School of Health, Isfahan University of Medical Sciences, Isfahan, Iran. ${ }^{2}$ Cardiac Rehabilitation Research Center, Cardiovascular Research Institute, Isfahan University of Medical Sciences, Isfahan, Iran. ${ }^{3}$ Gastroenterology and Hepatology Research Center, Isfahan University of Medical Sciences, Hezar-Jerib Ave., P.O. Box 319, Isfahan 81746-73461, Iran. ${ }^{4}$ Department of Pediatrics, Child Growth and Development Research Center, Research Institute for Primordial Prevention of Non-communicable Diseases, Isfahan University of Medical Sciences, Hezar-Jerib Ave., Isfahan 81746-73461, Iran.
Received: 5 September 2019 Accepted: 19 December 2019

Published online: 20 January 2020

\section{References}

1. Wright CM, Williams AF, Cole TJ (2013) Advances in growth chart design and use: the UK experience. In: Nutrition and Growth. Karger Publishers, 6674.

2. Bong Y, Shariff AA, Mohamed AM, Merican AF (2015) Malaysian growth centiles for children under six years old. Ann Hum Biol 42(2):108-115

3. Zong X-N, Li H (2013) Construction of a new growth references for China based on urban Chinese children: comparison with the WHO growth standards. PLoS One 8(3):e59569

4. Isojima T, Kato N, Ito Y et al (2016) Growth standard charts for Japanese children with mean and standard deviation (SD) values based on the year 2000 national survey. Clin Pediatr Endocrinol 25(2):71-76

5. Turck D, Michaelsen KF, Shamir R et al (2013) World health organization 2006 child growth standards and 2007 growth reference charts: a discussion paper by the committee on nutrition of the European society for pediatric gastroenterology, hepatology, and nutrition. J Pediatr Gastroenterol Nutr 57(2):258-264

6. De Onis M, Onyango A, Borghi E et al (2012) Worldwide implementation of the WHO child growth standards. Public Health Nutr 15(9):1603-1610

7. Growth Charts - Homepage. https://www.cdc.gov/growthcharts/. Accessed 21 Apr 2019.

8. Kuczmarski RJ (2002) 2000 CDC growth charts for the United States; methods and development.

9. Iftikhar S, Khan N, Siddiqui JS, Baig-Ansari N (2018) Development of growth charts of Pakistani children aged 4-15 years using quantile regression: a cross-sectional study. Cureus 10(2):e2138

10. Fetuga MB, Ogunlesi TA, Adekanmbi AF, Alabi AD (2011) Growth pattern of schoolchildren in Sagamu, Nigeria using the CDC standards and 2007 WHO standards. Indian Pediatr 48(7):523-528

11. Patel R, Unisa S (2014) Construction of national standards of growth curves of height and weight for children using cross-sectional data. Indian J Public Health 58(2):92-99

12. Aminorroaya A, Amini M, Naghdi $H$, Zadeh AH (2003) Growth charts of heights and weights of male children and adolescents of Isfahan, Iran. J Health Popul Nutr 21(4):341-346

13. Ayatollahi SMT (1995) Age standardization of weight-for-height in children using a unified Z-score method. Ann Hum Biol 22(2):151-162

14. Ayatollahi SMT, Ahmadi K (2001) Infants' growth charts for southern Iran. Ann Hum Biol 28(3):337-345

15. Ayatollahi SMT, Sharafi Z, Haem E (2015) Child weight growth chart and its associated factors in birth cohort of Maku using a growth curve model and LMS method. Global J Health Sci 7(6):181-186

16. Heydari S-T, Emamghoreishi F, Amini M (2009) Infants' growth charts in Jahrom, Iran. Iran J Pediatr 19(1):25-34

17. Kachoie A, Hamedi P, Mirmiran P, Azizi F (1997) Anthropometric evaluation, goiter and different stages of puberty in male students in east of Tehran (1994). Med J Shaheed Beheshti Univ 21:86-95

18. Organization WH (2006) WHO child growth standards: length/height-forage, weight-for-age, weight-for-length, weight-for-height and body mass index-for-age: methods and development.

19. El Mouzan M, Al Salloum A, Alqurashi M et al (2016) The LMS and Z scale growth reference for Saudi school-age children and adolescents. Saudi J Gastroenterol 22(4):331-336

20. Payande A, Tabesh H, Shakeri MT et al (2013) Growth curves of preschool children in the northeast of Iran: a population based study using quantile regression approach. Global J Health Sci 5(3):9-15

21. Owen CG, Martin RM, Whincup PH et al (2005) Effect of infant feeding on the risk of obesity across the life course: a quantitative review of published evidence. Pediatrics 115(5):1367-1377

22. Lucas A (2010) Growth and later health: a general perspective. In: Importance of growth for health and development. Karger Publishers, pp 1-11.

23. Stewart CD, Morris BH, Huseby $\vee$ et al (2009) Randomized trial of sterile water by gavage drip in the fluid management of extremely low birth weight infants. J Perinatol 29(1):26-32

24. Yang Z, Duan Y, Ma G et al (2015) Comparison of the China growth charts with the WHO growth standards in assessing malnutrition of children. BM Open 5(2):e006107 
25. Hosseini M, Carpenter RG, Mohammad K, Jones ME (1999) Standardized percentile curves of body mass index of Iranian children compared to the US population reference. Int J Obes 23(8):783-786

26. Al-Mazrou Y, Al-Amood MM, Khoja T et al (2000) Standardized national growth chart of 0-5 year-old Saudi children. J Trop Pediatr 46(4):212-218

27. Cacciari E, Milani S, Balsamo A et al (2002) Italian cross-sectional growth charts for height, weight and BMI (6-20y). Eur J Clin Nutr 56(2):171-180

28. Kløvgaard M, Nielsen NO, Sørensen TL et al (2018) Growth of children in Greenland exceeds the World Health Organization growth charts. Acta Paediatr 107(11):1953-1965

29. Davies PSW (2007) Growth charts for use in Australia. J Paediatr Child Health 43(1-2):4-5

30. Guo SS, Roche AF, Chumlea WMC et al (2000) Statistical effects of varying sample sizes on the precision of percentile estimates. Am J Hum Biol Off J Hum Biol Assoc 12(1):64-74

\section{Publisher's Note}

Springer Nature remains neutral with regard to jurisdictional claims in published maps and institutional affiliations.

\section{Submit your manuscript to a SpringerOpen ${ }^{\circ}$ journal and benefit from:}

- Convenient online submission

- Rigorous peer review

- Open access: articles freely available online

- High visibility within the field

- Retaining the copyright to your article

Submit your next manuscript at $\boldsymbol{\nabla}$ springeropen.com 